\title{
A Pilot Investigation of Occupational Therapy Students' Perceptions of Their Impact on Services to Older Adults
}

\author{
Dongni Li* \\ University of Sydney, Australia \\ Srivalli Nagarajan \\ University of Sydney, Australia \\ Sanetta du Toit \\ University of Sydney, Australia
}

\begin{abstract}
Practice education is an integral component of occupational therapy curricula to ensure graduates are competent in delivering effective and efficient services to their clients. This study aimed to understand occupational therapy students' perceptions of the impact of studentdelivered services for clients aged over 65 years. A case study design directed at in-depth exploration of undergraduate occupational therapy student experiences of working with older adults was employed. Semi-structured interviews were conducted with eight final-year students at an Australian university during 2015. Data were analysed using thematic analysis. The key finding was that students generally believed they contributed positively to aspects of clientservices during placements. Students reported on the development of competence during placement and the positive impact they had on services for older adults. The study highlighted the unique intergenerational relationship students had with older adults during their therapeutic encounters. However, very few participants recognised the importance and complexity of providing holistic services to older adults. Conclusion: There is potential to improve services for older adults by offering a greater number of placement opportunities involving students in direct client services. If occupational therapy students are better prepared, supported, and informed of the complexities associated with working with older adults, direct client-services rendered by students could potentially be enhanced. This will require ongoing collaboration between occupational therapy workforce, placement sites, and universities to align occupational therapy curricula with healthcare needs.
\end{abstract}

Keywords: aged care; occupational therapy; occupational therapy students; older adults; placement education; student-delivered services

${ }^{\star}$ Corresponding Author: Dongni Li, 5/164C Burwood Road, Concord, NSW 2137, Australia

Email: dongni.li94@gmail.com

Journal URL: http://e-learning.coventry.ac.uk/ojs/index.php/pblh

Li, D., Nagarajan, S., and du Toit, S. (2018) 'A pilot investigation of occupational therapy students' perceptions of their impact on services to older adults'. International Journal of Practice-based Learning in Health and Social Care, 6 (2), 14-30 


\section{(c) (i) (9) $\odot$}

( 2018 Dongni Li, Srivalli Nagarajan, and Sanetta du Toit. This Open Access article is distributed under the terms of the Creative Commons Attribution Attribution-NonCommercial No Derivatives 4.0 International License (https://creativecommons.org/licenses/bync-nd/4.0/), which permits unrestricted non-commercial use, distribution, and reproduction in any medium, provided the original work is properly cited and is unaltered. 


\section{Introduction}

Occupational therapy education involves a minimum of 1,000 hours of practice education (also referred to as fieldwork) (World Federation of Occupational Therapists 2016) where university students are placed in different clinical or community settings to learn knowledge and skills through participation in service-provision and dialogue with relevant stakeholders (Higgs 2011). While the primary outcome of placement is students' gain of practical experiences, a secondary outcome is that students add a unique contribution to client-services during their lengthy involvement in placement settings (Rodger, Fitzgerald et al. 2011).

Occupational therapy literature describes benefits of hosting students for the workplace as including students developing projects under guidance to improve workplace policies and therapy resources (Fortune and McKinstry 2012); supervisors experiencing intrinsic reward of contributing to the profession and developing skills in supervision, clinical reasoning, and timemanagement (Mason and Bull 2006, Thomas et al. 2007); and providing placement sites the potential for future recruitment (Hanson 2011). A different viewpoint is put forward by individual supervisors from different health professions who believe that student-supervision adds to their workload due to the time they spend on placement activities (Thomas et al. 2007, Trede et al. 2014). Hanson (2011) reports that this additional workload resulted in decreased service-related productivity of the occupational therapy supervisors. However, Mason and Bull (2006) suggest that the additional client-service activities undertaken by students compensated for this. Davies, Hanna and Cott (2011) confirmed the latter viewpoint, agreeing that although supervisors feel that more time is needed for student-supervision activities, it was in fact a 'different use of time', rather than diminished productivity. To understand the impact of placement students on servicerelated productivity, Rodger, Stephens et al. (2011) tracked the amount of occupational therapy client-consultations, treatment or other services provided by students and supervisors at placement sites in Queensland, Australia. They found no significant statistical difference to confirm the existence of an overall change in productivity. However, the impact of occupational therapy students on client-services in terms of both tangible (e.g. productivity and therapy outcomes) and intangible (e.g. therapeutic relationships) measures is still poorly understood.

In medical and allied health literature, multiple studies indicate that clients perceive that services provided by students are as effective as those delivered by clinicians (Barksby 2014, Kuan and O'Donnell 2007), and high client-satisfaction is achieved by quality service and extended consultation time students provide (Kent and Keating 2013, Mol, Peelen, and Kuyvenhoven 2011). Similarly Schindler and Sauerwald (2013) suggest that student-delivered occupational therapy assisted clients with mental illness to achieve education goals and secure employment. Although this study had only 48 participants, results were confirmed by both quantitative and qualitative data, collected by pre/post intervention surveys as well as post-intervention focus groups. Furthermore, an occupational therapy placement project, implemented by Olivier, Oosthuizen and Casteleiin (2007) in South Africa, claims that student-delivered skill-training sessions enabled adults with disabilities to improve their social and prevocational skills. However, results were mostly based on the researchers' observations and interpretation of participants' performance during the sessions; effectiveness of services was measured using a Likert Scale that included positively biased statements such as 'I enjoyed the activities we did in the sessions'; and neither was sample size stated, nor were the participants' opinions investigated in-depth. Results yielded from both studies cannot be generalised across all occupational therapy fields of practice, as the participants were sampled from specific population groups.

Clients' perspectives on the quality of services provided by occupational therapy students were studied in a cross-sectional study in Queensland, Australia (Rodger, Fitzgerald et al. 2011). Ninety-six percent of participants rated student-delivered services as good, excellent or exceptional post-discharge from service (Rodger, Fitzgerald et al. 2011). However, one could argue that the mid-point of the rating scale in the questionnaire - 'good' - is not a neutral word, which skewed clients' ratings positively. This survey method focused on the prevalence of clients' views on students, but did not explore stakeholders' perceptions of services in-depth. Controversially, Wearne (2011) states that supervising and answering questions from medical 
students would interrupt consultation sessions and compromise the quality of services in some circumstances.

Literature in other health professions suggests placement students spend more time with clients than staff, and support clients psychosocially by listening to their life stories (Scheffer et al. 2010, Trail Ross 2012). Nevertheless, neither the impact of students on client-services at placement sites, nor the perspectives of these students have been studied explicitly in the occupational therapy field. Past studies in other health disciplines discussed that students reported on valuable contributions they made to client-services, which were under-recognised by their supervisors (Csontó 2009, Siggins Miller Consultants, 2012). Therefore, a study exploring occupational therapy students' perspectives in-depth would build on existing studies of the clients' and supervisors' perspectives on the influence of placement-students on clientservices, and contribute to a more integrated understanding of student-delivered services at placement sites.

Meeting the healthcare needs of Australia's rapidly ageing population is a key target for the government (NSW Government 2008). Occupational therapists, one of the primary healthcare providers, work in various hospital and community settings, and deliver various services to older adults and their carers, such as adaptation of activities of daily living; assisting carers to continue caring; psychosocial interventions and life-style redesign (Mountain 2004). It is expected there will be a greater demand for an increased occupational therapy workforce in the future to serve older adults due to the longevity revolution (The Treasury 2015).

The pilot study reported in this article focused on the impact of third- and fourth-year occupational therapy undergraduate students on services for older adults during placements for three reasons: (1) the potential pressure this population group is expected to place on healthcare services in the future (Health Workforce Australia 2011); (2) the potential of utilising students as a resource to provide additional services to older adults; and (3) the demand for further explicit information about preparing graduates to work with this population group in the future. This study contributes to existing literature by enriching the picture of what experienced, pre-registration students bring to, and gain from, their therapeutic encounters with older adults and adding greater understanding of how this could contribute to practice and curriculum development. The research question for this study was: 'What are occupational therapy students' perceptions of their impact on client-services in placement settings where they interacted with adults older than 65 years?' As clients aged over 65 years were the focus of this study, they are referred to as 'older adults' from here on.Paragraph: use this for the first paragraph in a section, or to continue after an extract.

\section{Methods}

\section{Research design}

A case study design adopting a qualitative approach was followed, as it allowed for a deeper understanding of occupational therapy student experiences of working with older adults in different settings (Cresswell, 2013, Denzin and Lincoln 2011).

\section{Data collection method}

Semi-structured interviews were chosen to best capture participants' narratives of their perceptions of placement experiences and therapeutic encounters with older adults. It provided opportunity to further probe and ask participants to expand on their experiences, while allowing the comparison of responses from different participants to similar questions (Creswell 2014).

\section{Participant sampling, recruitment and ethics}

Participants were recruited from an Australian undergraduate occupational therapy program. This site was easily accessible, and had 131 third- and fourth-year students enrolled during 2014. Ethical approval was obtained from the university's human research ethics committee. 
Criterion-based sampling was used as it could maximise the variations of viewpoints with respect to placement sites and highlight similarities of participants experienced with a specific population - older adults (Patton 2015). Eligible students were third- or fourth-year undergraduate students who had completed a seven-week placement in settings servicing older adults.

To recruit students, posters were distributed by the first author in university campus and research invitations were sent to students' university email accounts by a third party - the university's occupational therapy discipline administrator. This protected the privacy of students and avoided coercion. Participation was voluntary. Interested parties were provided with a participant information statement and informed that no academic rewards were associated with this project. Written consent was gained before interviews.

The final sample consisted of eight fourth-year students whose profiles are displayed in Table 1. Students' ages ranged from 22 to 30 years, and they had diverse placement experience across acute, rehabilitation, and community settings. No third-year students volunteered to participate, possibly because they were on placement during the time and had not yet been exposed to older persons during placements. While only eight volunteers responded, recruitment ceased after analysing the eighth interview transcript as additional data no longer generated new codes and data had reached saturation (Creswell 2014).

Table 1. Profile of student participants

\begin{tabular}{|c|c|c|c|c|c|c|c|c|c|}
\hline & Student participant Anonym & A1 & A2 & A3 & A4 & A5 & A6 & A7 & A8 \\
\hline 高 & $\begin{array}{l}\text { Male } \\
\text { Female }\end{array}$ & $x$ & $x$ & $\mathrm{x}$ & $x$ & $x$ & $x$ & $x$ & $x$ \\
\hline 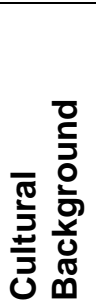 & $\begin{array}{l}\text { Caucasian } \\
\text { English second language } \\
\text { (Asian) } \\
\text { English second language for } \\
\text { one or both parents (Asian) }\end{array}$ & $x$ & $x$ & $x$ & $x$ & $x$ & $x$ & $\mathrm{x}$ & $\mathrm{x}$ \\
\hline 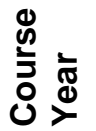 & Fourth-year undergraduate & $x$ & $x$ & $x$ & $x$ & $x$ & $x$ & $x$ & $x$ \\
\hline 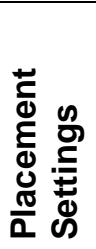 & $\begin{array}{l}\text { Geriatric acute } \\
\text { Rehabilitation (sub-acute) } \\
\text { Community aged care }\end{array}$ & $x$ & $x$ & $x$ & $x$ & $x$ & $x$ & $x$ & $x$ \\
\hline 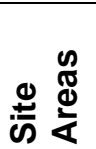 & $\begin{array}{l}\text { Metropolitan } \\
\text { Rural }\end{array}$ & $x$ & $x$ & $\mathrm{x}$ & $x$ & $x$ & $x$ & $x$ & $\mathrm{x}$ \\
\hline
\end{tabular}

\section{Data collection}

The three authors developed an interview guide, as displayed in Table 2, to capture participants' perceptions of their placement experiences, interactions with older adults, impact on client-services, placement performance, and any challenges they experienced. During data collection and analysis, the authors constantly reflected on the responses triggered by the interview questions and refined probing questions. 
Table 2. Illustrative Interview questions

\section{Guide for interviewing student participants}

1. Please tell me about your placement experience.

Additional probing questions:

- How did your responsibilities bring you in contact with people older than 65 years?

- What tasks did you do as an OT student on this placement?

2. Comparing with working with other clients, what was unique or new to your placement experience due to the fact that you worked with people older than 65 years?

Additional probing questions:

- What were the differences between this placement (working with older people) and your other placements?

- What were the similarities between this placement (working with older people) and your other placements?

- Would you please tell me more about it?

- How did you interact with the older people during the placement?

3. How did you impact on the occupational therapy services? Tell me examples. Additional probing questions:

- Considering you are only a student, not a qualified occupational therapist yet, how did you impact on the services for clients?

- Do you think the situation would be different if a qualified occupational therapist was there? Why did you think that way?

4. How do you perceive your performance in that placement? Additional probing questions:

- Why you believed you performance is ...?

- Would you please give some examples?

5. What were the challenges you experienced when working with people older than 65 years?

Additional probing questions:

- Would you please give a few examples?

- Why did you feel these challenging?

- How did you manage the challenges?

- What additional support you need from your supervisor to fulfil the requirements for your placement when working with people older than 65 years?

The interviews lasted for 45 minutes on average. The first author conducted all interviews telephonically, as all participants preferred this above face-to-face interviews due to convenience. The telephonic interview approach allowed participants' verbal cues and intonations to be recorded, which enabled the first author to interpret, clarify, and probe for further information (Opdenakker 2006). These verbal cues and intonations were noted in the transcripts, and were considered with the context and content of the interviews to interpret the meanings of the dialogue.

All interviews were audio-recorded and transcribed verbatim by the first author. Identifiable participant information was removed before the co-authors reviewed the transcripts. The coauthors listened to selected portions of audio-recordings, especially when participants raised different issues or viewpoints. Co-reviewing recordings ensured that the first author was guided 
to use adequate interview skills and interpreted significant verbal clues, intonations, and change of emotions appropriately during transcription and data analysis.

\section{Data analysis}

Data collection and analysis occurred concurrently. Thematic coding, based on Braun and Clarke's (2006) framework for thematic analysis, was used to interpret, compare, and analyse the commonalities and differences of participants' experiences of working with older adults. The first author familiarised herself with the data by repeated listening to audio-recordings, transcribing, documenting significant intonations, and reading transcripts. The first author preliminarily coded the data extracts using the computer software package NVivo® 10 . An example of the coding process followed is detailed in Appendix 1.

The co-authors reviewed the codes and transcripts repeatedly to merge similar codes, identify new codes, re-name the codes, and compare the codes to transcripts to ensure consistent coding. Through collaborative discussions, the authors refined codes, and grouped concepts based on their common features to generate lower level themes (categories). The lower level themes were then refined and collated into major themes until a consensus was reached (as illustrated in Table 3). This process of refining the codes and themes was also achieved using NVivo 10.

Table 3. Illustration of theme development

\begin{tabular}{|c|c|c|}
\hline Codes & $\begin{array}{ll}\text { - } & \text { Students bring different ideas/ } \\
\text { - } & \text { perspectives to service provision } \\
\text { - } & \text { Additional therapy sessions } \\
\text { - } & \text { Evidence-based practice } \\
\text { - } & \text { Transferring skills from other } \\
& \text { placement/work experiences }\end{array}$ & $\begin{array}{l}\text { - } \quad \text { Appreciation of students' work from supervisors } \\
\text { - } \quad \text { Appreciation of students' work from staffs } \\
\text { - } \quad \text { Trust and autonomy given by the supervisors to } \\
\text { placement students } \\
\text { - } \quad \text { Staffs value students' input in service provision } \\
\text { - } \quad \text { Grades on performance evaluation forms } \\
\text { - } \quad \text { Feedbacks from clients }\end{array}$ \\
\hline $\begin{array}{l}\text { Level } 1 \\
\text { theme }\end{array}$ & $\begin{array}{l}\text { Achievement of positive therapy } \\
\text { outcome }\end{array}$ & $\begin{array}{l}\text { Stakeholders' acknowledgement of students' } \\
\text { contributions }\end{array}$ \\
\hline $\begin{array}{l}\text { Level } 2 \\
\text { theme }\end{array}$ & \multicolumn{2}{|c|}{ Improved service-delivery } \\
\hline $\begin{array}{l}\text { Level } 3 \\
\text { theme }\end{array}$ & \multicolumn{2}{|c|}{ Positive contribution to client services } \\
\hline
\end{tabular}

\section{Trustworthiness}

Multiple strategies were adopted to ensure the credibility and trustworthiness of the study. Prior to data collection, the first author piloted an interview with a physiotherapy student to check for ambiguity and ensure clarity of wordings of the questions. This enhanced the first author's questioning and listening skills, and ability to conduct interviews effectively within appropriate time constraints. 
Throughout data collection and analysis, the first author engaged in a reflexive process by explicitly identifying her preconceptions derived from her placement experience of sharing supervisors' caseload in hospital geriatric acute wards and implementing interventions independently with minimal guidance. She consciously acknowledged these experiences might bias her interpretations of participants' experiences by having pre-assumptions. Therefore she engaged in regular meetings with the co-authors to (1) discuss interpretations of the transcripts, codes, and themes, (2) constantly reflect on the alignment of interview questions with research purpose and theoretical approach, and (3) understand the context from which participants detailed their experiences and perspectives. The codes and themes were refined by all authors collaboratively until mutual agreement was reached (Creswell 2014).

\section{Findings}

The overarching theme was that students generally believed they contributed positively to client-services during their placements. However during the interviews, many participants initially focused more on their competence-development and had to be prompted to expand on their therapeutic encounters with older adults. The three subthemes identified relate to areas of the unique intergenerational interactions between students and older adults, service delivery, and competence development (see Figure 1).

Figure 1: Identified theme and sub-themes

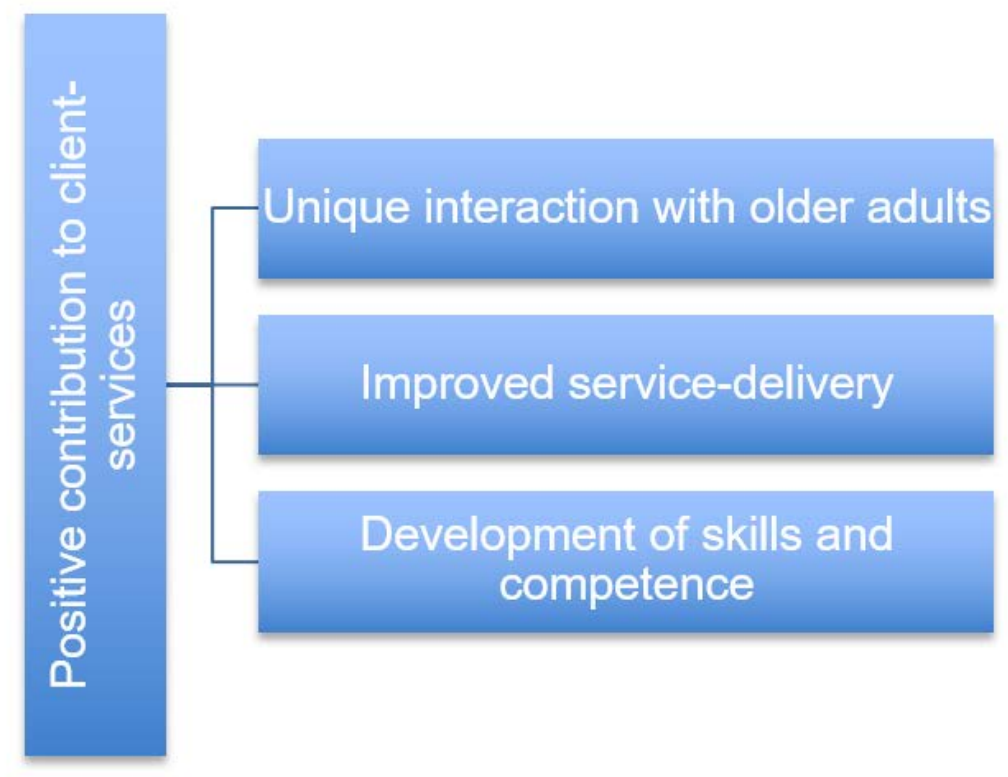

\section{Unique interaction with older adults}

Several participants believed that the age difference between older adults and young students added an additional quality to the therapeutic relationship. These intergenerational interactions were best described by the following participants:

They are all older and wiser than you ... [you] interact with them on a different level ... It's easy to develop rapport with the older people because they got so many life experiences (Participant 6, Rehabilitation setting).

You felt warmth from them, because you could be the same age as their grandchildren ... She was talking to me about her granddaughter who wasn't far off my age, ... it's that connection that people make (Participant 7 , Community setting). 
In some cases, older clients' satisfaction towards student-delivered services also appeared to be linked to a sense of being valued, as:

[Clients] enjoyed that they were helping [students] learn - a sense of being useful (Participant 7, Community setting).

Most students also identified that the intergenerational relationship and their student identity were contributing factors that placed students in a unique position to support older adults psychosocially:

There were no expectations that I would be able to get through most of the clients and there was no expectation that I could do things quickly, so I could take a bit more time to develop into a conversation with the client, build rapport a bit better (Participant 1, Rehabilitation setting).

Having respect for them and their experiences and just trying to see them as a person, not a patient ... It might be harder for [qualified therapists] because they've got an actual title and they're strict in a certain way ... I didn't have that same authority as the other staff, so that was easier for me to interact with [patients] on that level ... trying to validate their feelings. Of course they're gonna be upset if they can't go home where they lived for 60 years, and you know you can't just brush that off as something that's not important ... (Participant 6, Rehabilitation setting).

Although many unique aspects of working with older adults were identified, half of the students still had the perception that there was not much difference between working with older people and other client populations, as best described by Participant 1:

You're just working with different personality types and different issues. When you get past the age issue... it was just working with people (Participant 1, Acute setting).

\section{Improved service-delivery}

All students believed their input facilitated effective service outcomes, and specifically indicated they applied knowledge learnt from university and previous placement experiences to improve services for the older persons. For example, Participant 4 recommended alternative interventions for clients, based on current evidence-based practice covered during university lectures. Participant 7 transferred skills gained from a previous placement experience to expand the provision of services at her current placement site:

[Client] had lots of psychological issues. I found my mental health placement skills came in very handy. ... I have red flagged [her psychological issues] to my supervisor (Participant 7 , Community setting).

The input of students translated into contributions to positive therapy outcomes for clients as additional therapeutic contacts were provided:

[Some clients] could only get [therapy sessions from qualified therapists] once every second day ... I could see [clients] twice a day because I had that extra time ... It does make a difference [to therapy outcome] - how early and how regularly [clients] get that therapy (Participant 6, Rehabilitation setting).

Gains in service delivery were also reflected by supervisors' acceptance of students' suggestions of alternative interventions for clients, and good feedback received from clients:

[Client] thanked me and told me "You'd be great in the hospital" ... She's really happy and appreciates the way I talk to her ... In the last day she said "Oh, I'm gonna miss you" (Participant 7 , Community setting). 
[My supervisor prescribed] a bathroom modification ... I figured out another way that gave more circulation space. ... and she agreed (Participant 4 , Community setting).

In addition, many students believed that they contributed to services at placement sites by sharing their supervisors' caseload:

[My supervisor] had the time to participate in training, because I was taking a fair chunk of the caseload. ... She was [also] able to pick up extra clients on her caseload (Participant 8, Rehabilitation setting).

Particularly, Participant 6 reported on the insufficient access to occupational therapists in rural areas for providing adequate services to older clients:

[There was] a sudden influx of stoke patients... [My supervisor] said she was really grateful that I was able to take on that and get some confidence after a couple of weeks and then do therapies by myself (Participant 6, Rehabilitation setting).

This indicated that students increased the institution's capacity to service more older adults by sharing their supervisors' caseload.

\section{Development of skills and competence}

Findings revealed that participants focused mostly on the skills and competence they developed during interviews. Students acknowledged that supervisors' continuous support during the initial weeks was key to developing competence for implementing effective interventions:

I reported to [my supervisor] after every session, and she advised me, "Oh, that's good, Keep doing that"; or "add some more weights"; or "add some more repetitions" (Participant 6, Rehabilitation setting).

One student specifically captured confidence, and pride in competence, gained during the placement.

I felt like I was his occupational therapist. ... I do feel like [the interventions and outcome] would work out the same whether [my supervisor] had him or I had him (Participant 4, Acute setting).

Students stated their flexibility of client-centeredness improved when they were familiar with their placement contexts. For example, three participants mastered aspects of client-centred practice by adopting an inclusive service approach. This was specifically evident in how they embraced family, culture, and religion factors and incorporated these supportive values and beliefs into their service provision.

We recommended certain equipment. ... [Client] would have refused out of cultural reasons. We would have to advise the family that we didn't think it was safe for him to do it any other way, we had to encourage the family member to slowly encourage the client, which took time and education, and it was a lot of trying to get the family on-board first (Participant 8, Rehabilitation setting).

We really recommended a hoist, [Client] refused ... "No, my son can carry me". ... Although the son had severe back issues, he was still willing to continue that. ... [It's] their [Vietnamese] culture that they took care of their family no matter what ... We have to change our approach and adapt what we suggested (Participant 8 , Rehabilitation setting).

Family members were perceived as an important 'go-to' when participants experienced difficulties interacting with older adults:

Depending on if [clients] have dementia or depression, some of them may respond in ways difficult to decipher ... You would try to have family members there while 
you were doing the interview or interventions ... because the family knows what the context is ... and might have strategies to understand [client] better (Participant 3 , Acute setting).

Six students reflected that the ability to provide appropriate interventions independently was gained towards the end of placement when their practical skills were much more developed. For example:

At the beginning, [my supervisor] would check [my work] and there would be [parts] that she would want me to fix. But by the end, I was able to produce work that she could just read over and go "Yes, I'm happy with that" (Participant 4, Community setting).

These were all kind of done independently within the one session rather than needing constant check of "Okay" from my supervisor. ... I think that's one instance, which was towards the end of the placement where I really saw all my skills coming together into one kind of cohesive moment (Participant 8 , Rehabilitation setting).

Students felt their increased skills contributed to client-services and that this was confirmed by supervisors and staff member's appreciation of their work:

[My supervisor] even says that if it was possible she would have hired me. (Participant 1, Acute setting).

It was quite a close-knit staff network and I think after a while they've seen what I was doing and that I was -- capable and so they did listen. I'm not sure if they gave the same weight for my work as they would to someone else, but they treated me with respect (Participant 6, Rehabilitation Setting).

Other evidence reported also included good grades on placement performance evaluation forms.

While contributions to client-services were identified predominantly, participants also reflected on the challenges they experienced during placements. Two participants thought their serviceapproach was rigid and they were less flexible to provide client-centred services:

I will only [ask] information related to the [assessment] form because I don't know what else is needed... but my supervisor knows what else we should ask about (Participant 5, Community setting).

\section{Discussion}

This study specifically examined the perceived impact of senior occupational therapy placement students in settings servicing older adults. Participants in this study believed that in addition to developing professional competence, they also made positive contributions to client-services while they were on placement.

Findings from this study were similar to a previous study focusing on outcomes associated with student-delivered occupational therapy services (Rodger, Fitzgerald et al. 2011), and confirmed the students' perceived competence in providing quality services to clients when adequate supervision and guidance were in place. While previous studies examined the effectiveness of student-implemented interventions quantitatively using various outcome measures (Schindler and Sauerwald 2013, Olivier, Oosthuizen and Casteleijn 2007), this study provides qualitative evidence and adds new insights supporting that students' perceived their involvement in clientservices during placements could contribute positively to the psychosocial wellbeing of older adults. For example, participants reported that they had the privilege of spending more time with clients to build rapport and support any additional psychosocial needs, which is congruent with medical and nursing literature (Scheffer et al. 2010, Trail Ross 2012). This also backed Freeth 
et al.'s (2001) findings of student-delivered nursing services where clients valued the extra service time and less-hurried approach offered by students in comparison to qualified staff.

The student-client relationships and rapport were also enhanced by opportunities for intergenerational interaction. The nature of these interactions supports Erikson's theory that older adults experience the need to share their wisdom with the younger generation (Berk 2017). Participants felt older adults perceived themselves as mentors that contributed to students' training when they offered opportunities for students to practice their skills and knowledge. This sense of contributing to students' learning was also noted in a review of patients' roles in education of medical students (Spencer et al. 2000). Such intergenerational interaction may benefit students' learning experience, as clients appear to exhibit more tolerance, lower expectations, and higher satisfaction towards student-delivered services. Additionally, participants' perceived identities as 'student therapists in-training', combined with the sense that older adults acted as 'mentors', and the extra respect participants showed towards the older adults, positively impacted potential power imbalances between clients and 'therapy providers'. Thus participants believed that they were in a better position than their supervisors to provide client-centered services, because of more power-balanced relationships with clients. This novel aspect of student practitioner to client relationships could support insights into building client-centered practice and needs further investigation as clients need to be recognised as experts of their own lives.

While Csontó (2009) found that students did not overtly consider spirituality while working with clients due to omitting spirituality from assessment forms, two participants in this study attempted to address older adults' spiritual needs by spending extra time with them, being empathic to their life stories, and addressing their psychosocial needs. They reported being in better positions than their supervisors to devote more time in client-services when their supervisors were pressed for time, due to the fast work-pace in acute settings and the shortage of staff in rural areas (Roots and Li 2013). This could indicate that shortage of time was a limiting factor for qualified therapists to consider clients' spirituality needs and provide a more holistic service in these settings. Future studies could investigate the feasibility of using neargraduate occupational therapy students as an alternative resource to provide specific aspects of client-services during staff shortages.

Evidence presented in this study suggests that students were exposed to a range of placement sites where they required unique skills to work with older adults and their families from diverse cultures. However, rather than identifying their specific contributions to the holistic care of the older adults, most students focused on gains in general skills associated with the Australian occupational therapy competency standards (Occupational Therapy Australia 2018). For example, all participants reported the development of skills to conduct different assessments, prescribing equipment and modifications, and delivering particular therapies, but very few attempted to acknowledge the complex and multi-faceted care needs of older adults. In particular, only two students attempted to incorporate spirituality into service planning, and only one student referred to the unique needs of older adults, such as acknowledging and supporting clients' desire of 'ageing in place'. Another student identified the role of acting as an advocate in educating and enabling family to support better care for older adults in a culturally sensitive manner. The fact that no students identified the role of family support in identifying care needs of older adults is disconcerting. Although many participants claimed that they developed skills to service older adults independently during placements, these skills would only amount to fragmented care approaches and specific occupational therapy tasks or outcomes to which they contributed. As such, a well-supported supervision approach is crucial to facilitate students' learning experiences during placements as well as to strengthen students' capacity to meet the holistic service needs of older adults and their families. It would be worth exploring how curriculum development could support occupational therapy students to develop a skill set geared towards addressing needs specific to older adults.

This study investigated the perceived contributions of students to older adults, which are underrecognised in current occupational therapy literature. Longevity and expansion of aged care services necessitate the development of a skillset to enhance the quality of student-delivered services to older adults (du Toit and Wilkinson 2011). As the proportion of older Australians is 
predicted to double by 2056 (Australian Bureau of Statistics 2009), there would be a greater service demand from older people. Adequately guiding and supporting students to provide quality services for older adults would be a proactive approach to simultaneously equip occupational therapy students and provide additional services to clients with limited cost implications.

\section{Study limitations and future work}

As this study only included eight fourth-year undergraduate occupational therapy students at one Australian university, the findings are not necessarily generalisable to all final year undergraduate students. Attempts to maximise variation in occupational therapy students should be made to allow greater generalisability. This could include students from different placement settings, different geographic locations, and at different stages of their university degree. There is also a likely bias in that students who agreed to participate may have been more likely to have had positive experiences which may not reflect the opinion of all students in this cohort. To allow for generalisation to a larger population, student impact on service delivery should be investigated using a quantitative approach. Further occupational therapy studies should examine: (1) the impact of students on client-services by triangulating the perspectives of students, supervisors, and clients from same placement sites; (2) the consistency of students, supervisors, and clients' perceptions of students' impact on client services across different clinical settings; (3) family members perspectives; and (4) the potential for students to provide culturally friendly care to clients from different cultural backgrounds.

\section{Conclusion}

This article presents an account of occupational therapy students' perceptions of their positive contributions to services for older adults. In particular, all participants agreed they provided adequate services to promote older adults' occupational performance and participation, and highlighted their perceived contributions to meeting the psychosocial needs of older adults and general contributions to the placement sites. However, very few recognised the complexity of providing holistic care to older adults; and most participants only focused on their professional skill development associated with therapeutic interventions in general, and not per se for older adults. These findings are important for two reasons: (1) there is potential to improve services for older adults if more placement opportunities are offered and more students are involved in direct client-services; (2) the quality of client-services may be enhanced if students are better informed of the complexities associated with working with older adults and better supported by their supervisors during placements. We encourage placement sites and universities to further support occupational therapy students' competence development, and enhance quality of student-provided services by better preparing them for the holistic service needs of older adults and the multifarious nature of working with older people. On-going collaboration between industry and universities to align occupational therapy curricula with future healthcare needs is therefore essential.

\section{Acknowledgements}

The authors wish to sincerely thank the occupational therapy students who contributed their knowledge and experience in this study. 


\section{References}

Atwal, A., McIntyre, A., Craik, C., and Hunt, J. (2008) 'Older adults and carers' perceptions of pre-discharge occupational therapy home visits in acute care'. Age and Ageing [online] 37 (1), 72-76. https://doi.org/10.1093/ageing/afm137 [1 July 2016]

Australian Bureau of Statistics (2009) Future Population Growth and Ageing. (Cat. no. 4102.0). Canberra, Australia: Australian Bureau of Statistics

Barksby, J. (2014) 'Service users' perceptions of student nurses'. Nursing Times, 110 (19), 2325

Berk, L. (2017) Development Through the Lifespan. 7th edn. New York: Pearson

Braun, V. and Clarke, V. (2006) 'Using thematic analysis in psychology'. Qualitative Research in Psychology [online] 3 (2), 77-101 https://doi.org/10.1191/1478088706qp063oa [1 July 2016]

Creswell, J.W. (2013) Qualitative Inquiry and Research Design: Choosing Among Five Approaches. 3rd edn. Thousand Oaks, CA: Sage

Creswell, J.W. (2014) Research Design: Qualitative, Quantitative, and Mixed Methods Approaches. 4th edn. Thousand Oaks, CA: Sage

Csontó, S. (2009) 'Occupational therapy students' consideration of clients' spirituality in practice placement education'. The British Journal of Occupational Therapy, 72 (10), 442-449 https://doi.org/10.1177/030802260907201005

Davies, R., Hanna, E., and Cott, C. (2011) '“They put you on your toes": Physical Therapists' perceived benefits from and barriers to supervising students in the clinical setting'. Physiotherapy Canada, 63 (2), 224-233 https://doi.org/10.3138/ptc.2010-07

Denzin, N. and Lincoln, Y. (2011) 'The Discipline and Practice of Qualitative Research'. in The SAGE Handbook of Qualitative Research. Ed. by Denzin, N. and Lincoln, Y. 4th edn. Thousand Oaks, CA: Sage, 1-19

du Toit, S. and Wilkinson, A. (2011) 'Promoting an appreciation for research-related activities: The role of occupational identity'. The British Journal of Occupational Therapy, 74 (10), 489-493 https://doi.org/10.4276/030802211X13182481842029

Fortune, T. and McKinstry, C. (2012) 'Project-based fieldwork: Perspectives of graduate entry students and project sponsors'. Australian Occupational Therapy Journal, 59 (4), 265275 https://doi.org/10.1111/i.1440-1630.2012.01026.x

Freeth, D., Reeves, S., Goreham, C., Parker, P., Haynes, S., and Pearson, S. (2001) "'Real life" clinical learning on an interprofessional training ward'. Nurse Education Today [online] 21 (5), 366-372 https://doi.org/10.1054/nedt.2001.0567 [1 July 2016]

Hanson, D.J. (2011) 'The perspectives of fieldwork educators regarding Level II fieldwork students'. Occupational Therapy in Health Care, 25 (2), 164-177 https://doi.org/10.3109/07380577.2011.561420

Health Workforce Australia (2011) Mapping Clinical Placements: Capturing Opportunities for Growth. Adelaide, Australia: Health Workforce Australia

Higgs, J. (2011) Professional and Practice-based Education at Charles Sturt University. Sydney, Australia: 2e The Education For Practice Institute, CSU, Sydney Olympic Park 
Kent, F. and Keating, J. (2013) 'Patient outcomes from a student-led interprofessional clinic in primary care'. Journal of Interprofessional Care 27 (4), 336-338 https://doi.org/10.3109/13561820.2013.767226

Kuan, S. and O'Donnell, J. (2007) 'Medical students in the emergency department: how do patients view participation in clinical teaching?' Irish Medical Journal, 100 (8), 560-561

Lewis, S.C. (2003) Elder Care in Occupational Therapy. 2nd edn. Thorofare, NJ: SLACK

Mason, L. R. and Bull, B. J. (2006) 'Practice placement education in mental health: The educator's experience'. The British Journal of Occupational Therapy [online] 69 (1), 2230 https://doi.org/10.1177/030802260606900105

Mol, S.S.L., Peelen, J.H., and Kuyvenhoven, M.M. (2011) 'Patients' views on student participation in general practice consultations: A comprehensive review'. Medical Teacher, 33 (7), e397-e400 https://doi.org/10.3109/0142159X.2011.581712

Mountain, G.A. (2004) Occupational Therapy with Older People. London: Whurr

NSW Government (2008) Budget Estimates 2008-09 - NSW Treasury. [online] available from <http://www.treasury.nsw.gov.au/budget_papers/Budget_Papers_2008-09/bp3/200809_budget_paper_3> [1 July 2016]

Occupational Therapy Australia (2018) Australian Occupational Therapy Competency Standards 2018. [online] available from https://www.occupationaltherapyboard.gov.au/codes-guidelines/competencies.aspx [16 September 2018]

Olivier, M., Oosthuizen, L., and Casteleijn, D. (2007) 'Occupational therapy students' contribution towards enabling potential in a semi-rural community'. Work 29 (1), 63-68

Opdenakker, R. (2006) 'Advantages and disadvantages of four interview techniques in qualitative research'. Forum: Qualitative Social Research [online] 7 (4), Article 11. available from <http://www.qualitative-research.net/index.php/fqs/article/view/175/391> [1 July 2016]

Patton, M.Q. (2015) Qualitative Research and Evaluation Methods: Integrating Theory and Practice. 4th edn. Thousand Oaks, CA: Sage

Rodger, S., Fitzgerald, C., Davila, W., Millar, F., Springfield, K., Thomas, Y., ... Greber, C. (2011) 'Consumers' perspectives of quality in student delivered occupational therapy services'. Focus on Health Professional Education [online] 13 (2), 37-52. available from <http://search.informit.com.au.ezproxy2.library.usyd.edu.au/documentSummary; dn=537 891909705604;res=IELHEA $\geq$ [1 July 2016]

Rodger, S., Stephens, E., Clark, M., Ash, S., and Graves, N. (2011) 'Occupational therapy students' contribution to occasions of service during practice placements in health settings'. Australian Occupational Therapy Journal, 58 (6), 412-418 https://doi.org/10.1111/j.1440-1630.2011.00971.x

Roots, R.K. and Li, L.C. (2013) 'Recruitment and retention of occupational therapists and physiotherapists in rural regions: A meta-synthesis'. BMC Health Services Research, 13 (59) https://doi.org/10.1186/1472-6963-13-59

Scheffer, C., Edelhäuser, F., Tauschel, D., Riechmann, M., and Tekian, A. (2010) 'Can final year medical students significantly contribute to patient care? A pilot study about the perception of patients and clinical staff'. Medical Teacher, 32 (7), 552-557 https://doi.org/10.3109/01421590903437170 
Schindler, V.P. and Sauerwald, C. (2013) 'Outcomes of a 4-year program with higher education and employment goals for individuals diagnosed with mental illness'. Work, 46 (3), 325336 doi: 10.3233/WOR-121548

Siggins Miller Consultants (2012) Promoting Quality in Clinical Placements: Literature Review and National Stakeholder Consultation. Adelaide, Australia: Health Workforce Australia

Spencer, J., Blackmore, D., Heard, S., McCrorie, P., McHaffie, D., Scherpbier, A., ... Southgate, L. (2000) 'Patient-oriented learning: A review of the role of the patient in the education of medical students'. Medical Education, 34 (10), 851-857. https://doi.org/10.1046/j.1365-2923.2000.00779.x

The Treasury (2015) 2015 Intergenerational Report Australia in 2055. [online] available from < http://apo.org.au/node/53411 [16 September 2018]

Thomas, Y., Dickson, D., Broadbridge, J., Hopper, L., Hawkins, R., Edwards, A., and McBryde, C. (2007) 'Benefits and challenges of supervising occupational therapy fieldwork students: supervisors' perspectives'. Australian Occupational Therapy Journal 54 (S1), s2-s12 https://doi.org/10.1111/j.1440-1630.2007.00694.x

Trail Ross, M.E. (2012) 'Linking classroom learning to the community through service learning'. Journal of Community Health Nursing [online] 29 (1), 53-60 https://doi.org/10.1080/07370016.2012.645746

Trede, F., McEwen, C., Kenny, A. and O'Meara, P. (2014) 'Supervisors' experiences of workplace supervision of nursing and paramedic students in rural settings: A scoping review'. Nurse Education Today, 34 (5), 783-788 https://doi.org/10.1016/i.nedt.2013.10.003

Wearne, S.M. (2011) 'In-practice and distance consultant on-call general practitioner supervisors for Australian general practice?' The Medical Journal of Australia [online]195 (4), 224-228. available from <https://www.mja.com.au/journal/2011/195/4/practice-and-distance-consultant-callgeneral-practitioner-supervisors-australian> [1 July 2016]

World Federation of Occupational Therapists (2016) Revised Minimum Standards for the Education of Occupational Therapists. [online] available from <http://www.wfot.org/Store/tabid/61/CategorylD/1/ProductID/55/Default.aspx> [29 January 2018] 


\section{APPENDIX 1 - Sample coding}

\begin{tabular}{|c|c|}
\hline Codes & Quotes \\
\hline $\begin{array}{l}\text { Students bring } \\
\text { different } \\
\text { ideas/ } \\
\text { perspectives } \\
\text { to service } \\
\text { provision }\end{array}$ & $\begin{array}{l}\text { "I felt that I was able to significantly contribute to supporting the } \\
\text { family by explaining to the social worker their cultural practice } \\
\text { whereas the social worker wasn't going to consider as much } \\
\text { because she was thinking the other services whereas I feel I } \\
\text { was able to communicate in more of the cultural need that } \\
\text { that particular client had." } \\
\text { "I told the supervisor 'or maybe we could do it this way then, have the } \\
\text { stairs a bit longer' and then she agreed. And then she said, } \\
\text { you know 'Thanks, xxxx. That's a good idea.' So that } \\
\text { suggestion was put in place and referred to the home } \\
\text { modification." } \\
\text { "My supervisor hadn't heard of it before but I have through our study } \\
\text { at university. It might be something new, and so I was able to } \\
\text { put a different perspective on things and maybe -- And they } \\
\text { did take my suggestions seriously. So I think once or twice } \\
\text { they said, "Yeah, let's look into that." And I did and then we } \\
\text { were able to do an intervention with the client or use another } \\
\text { piece of equipment that l'd heard of." }\end{array}$ \\
\hline $\begin{array}{l}\text { Extended therapy } \\
\text { time }\end{array}$ & $\begin{array}{l}\text { "Because I was a student, there were no expectations that I would be } \\
\text { able to get through most of clients and there was no } \\
\text { expectation that I could do things quickly, so I could take a bit } \\
\text { more ... And build that rapport a bit better, it wasn't-- well, } \\
\text { acute is a very fast-pace setting, I wasn't expected to work at } \\
\text { the same pace that my supervisor did." } \\
\text { "Yeah and because all of the staff, you know, was so pressed for } \\
\text { time- and I was able to spend a little bit more time with } \\
\text { them... the staff who -- they had all the extra demand, so I } \\
\text { think having like four or five patients, I could just, you know, } \\
\text { split my time up between them and, you know, have that extra } \\
\text { time. It wasn't much extra time, but you know I didn't have to } \\
\text { rush between people when I could - you know, spend a little } \\
\text { bit of extra time helping them if they needed" }\end{array}$ \\
\hline $\begin{array}{c}\text { Additional therapy } \\
\text { sessions }\end{array}$ & $\begin{array}{l}\text { "I think with stroke, well, I was told that it's the earlier the better, and } \\
\text { the more intense therapy you get, the better... OT could only } \\
\text { get once a day; once every second day. Except the ones I } \\
\text { was seeing, I could see them twice a day because I had that } \\
\text { extra time. So I think, yeah, it does make a difference, how } \\
\text { early and how... how regularly they get that therapy" }\end{array}$ \\
\hline
\end{tabular}

